\title{
Not COVID Toes: Pool Palms and Feet in Pediatric Patients
}

\author{
Stephanie S. Lee, MD; Jennifer Mancuso, MD; Alexis Tracy, MD; Lawrence F. Eichenfield, MD
}

So-called COVID toes is probably the most publicized cutaneous manifestation of COVID-19. The parents of 4 patients pursued dermatology evaluation with concerns about COVID-19 infection in their children who presented with symmetric, focal, erythematous lesions of the hands or feet, or both. We elicited a history of extended time in swimming pools for the 4 patients that was associated with COVID-19 restrictions during summer months of the pandemic and recognized findings of frictional and pressure-induced erythema and scaling, leading to a diagnosis of pool palms and feet-an extension of pool palms. It is important to recognize this diagnosis and provide reassurance to the patients and caregivers because the condition warrants no notable workup or therapeutic intervention.

Cutis. 2021;108:276, 295.

\section{Practice Gap}

Frictional, symmetric, asymptomatic, erythematous macules of the hands and feet can be mistaken for perniolike lesions associated with COVID-19, commonly known as COVID toes. However, in a low-risk setting without other associated symptoms or concerning findings on examination, consider and inquire about frequent use of a swimming pool. This activity can lead to localized pressure- and friction-induced erythema on palmar and plantar surfaces, called "pool palms and feet," expanding on the already-named lesion "pool palms" — an entity that is distinct from COVID toes.

\section{Technique for Diagnosis}

We evaluated 4 patients in the outpatient setting who presented with localized, patterned, erythematous lesions of the hands or feet, or both, during the COVID-19 pandemic. The parents of our patients were concerned that the rash represented "COVID fingers and toes," which are perniolike lesions seen in patients with suspected or confirmed current or prior COVID-19. ${ }^{1}$

Pernio, also known as chilblains, is a superficial inflammatory vascular response, usually in the setting of exposure to cold. ${ }^{2}$ This phenomenon usually appears as erythematous or violaceous macules and papules on acral skin, particularly on the dorsum and sides of the fingers and toes, with edema, vesiculation, and ulceration in more severe cases. Initially, it is pruritic and painful at times.

With COVID toes, there often is a delayed presentation of perniolike lesions after the onset of other COVID19 symptoms, such as fever, cough, headache, and sore throat. ${ }^{2,3}$ It has been described more often in younger patients and those with milder disease. However, because our patients had no known exposure to SARS-CoV-2 or other associated symptoms, our suspicion was low.

The 4 patients we evaluated-aged 4 to 12 years and in their usual good health-had blanchable erythema of the palmar fingers, palmar eminences of both hands, and plantar surfaces of both feet (Figure). There was no swelling or tenderness, and the lesions had no violaceous coloration, vesiculation, or ulceration. There was no associated pruritus or pain. One patient reported rough texture and mild peeling of the hands.

Upon further inquiry, the patients reported a history of extended time spent in home swimming pools, including holding on to the edge of the pool, due to limitation of activities because of COVID restrictions. One parent noted that the pool that caused the rash had a rough nonslip surface, whereas other pools that

CONTINUED ON PAGE 295

From the Division of Pediatric and Adolescent Dermatology, Departments of Dermatology and Pediatrics, University of California, San Diego, and Rady Children's Hospital-San Diego.

The authors report no conflict of interest.

Correspondence: Stephanie S. Lee, MD, Rady Children's Hospital-San Diego, 3020 Children's Way, Mail Code 5092, San Diego, CA 92123 (slee7@rchsd.org).

doi:10.12788/cutis.0385 

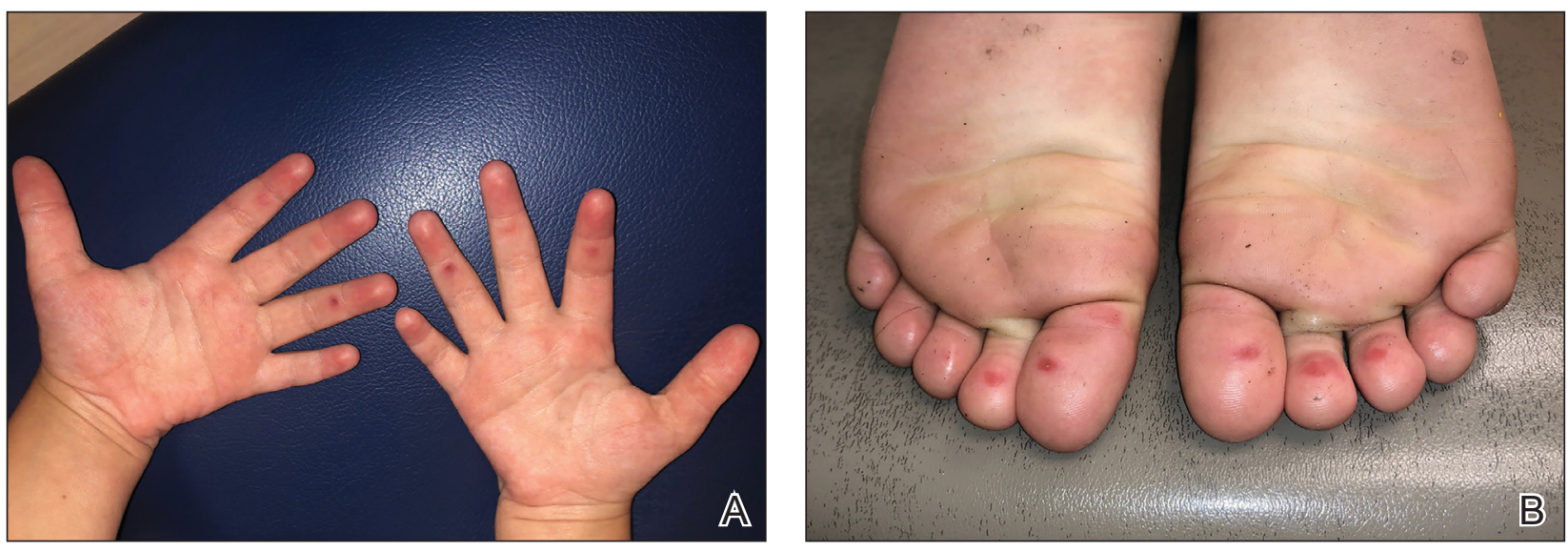

Pool palms and feet. A, Blanchable erythematous macules on the volar aspects of the fingers and erythema of the palms. B, Blanchable erythematous macules on the plantar surfaces of the toes.

the children used, which had a smoother surface, caused no problems.

The morphology of symmetric blanching erythema in areas of pressure and friction, in the absence of a notable medical history, signs, or symptoms, was consistent with a diagnosis of pool palms, which has been described in the medical literature. ${ }^{4-9}$ Pool palms can affect the palms and soles, which are subject to substantial friction, especially when a person is getting in and out of the pool. There is a general consensus that pool palms is a frictional dermatitis affecting children because the greater fragility of their skin is exacerbated by immersion in water. ${ }^{4-9}$

Pool palms and feet is benign. Only supportive care, with cessation of swimming and application of emollients, is necessary.

Apart from COVID-19, other conditions to consider in a patient with erythematous lesions of the palms and soles include eczematous dermatitis; neutrophilic eccrine hidradenitis; and, if lesions are vesicular, hand-foot-andmouth disease. Juvenile plantar dermatosis, which is thought to be due to moisture with occlusion in shoes, also might be considered but is distinguished by more scales and fissures that can be painful.

Location of the lesions is a critical variable. The patients we evaluated had lesions primarily on palmar and plantar surfaces where contact with pool surfaces was greatest, such as at bony prominences, which supported a diagnosis of frictional dermatitis, such as pool palms and feet. A thorough history and physical examination are helpful in determining the diagnosis.

\section{Practical Implications}

It is important to consider and recognize this localized pressure phenomenon of pool palms and feet, thus obviating an unnecessary workup or therapeutic interventions. Specifically, a finding of erythematous asymptomatic macules, with or without scaling, on bony prominences of the palms and soles is more consistent with pool palms and feet.

Pernio and COVID toes both present as erythematous to violaceous papules and macules, with edema, vesiculation, and ulceration in severe cases, often on the dorsum and sides of fingers and toes; typically the conditions are pruritic and painful at times.

Explaining the diagnosis of pool palms and feet and sharing one's experience with similar cases might help alleviate parental fear and anxiety during the COVID-19 pandemic.

\section{REFERENCES}

1. de Masson A, Bouaziz J-D, Sulimovic L, et al; SNDV (French National Union of Dermatologists-Venereologists). Chilblains is a common cutaneous finding during the COVID-19 pandemic: a retrospective nationwide study from France. J Am Acad Dermatol. 2020;83:667-670. doi:10.1016/j.jaad.2020.04.161

2. Freeman EE, McMahon DE, Lipoff JB, et al; American Academy of Dermatology Ad Hoc Task Force on COVID-19. Pernio-like skin lesions associated with COVID-19: a case series of 318 patients from 8 countries. J Am Acad Dermatol. 2020;83:486-492. doi:10.1016/j .jaad.2020.05.109

3. Freeman EE, McMahon DE, Lipoff JB, et al. The spectrum of COVID-19-associated dermatologic manifestations: an international registry of 716 patients from 31 countries. J Am Acad Dermatol. 2020;83:1118-1129. doi:10.1016/j.jaad.2020.06.1016

4. Blauvelt A, Duarte AM, Schachner LA. Pool palms. J Am Acad Dermatol. 1992;27:111. doi:10.1016/s0190-9622(08)80819-5

5. Wong L-C, Rogers M. Pool palms. Pediatr Dermatol. 2007;24:95. doi:10.1111/j.1525-1470.2007.00347.x

6. Novoa A, Klear S. Pool palms. Arch Dis Child. 2016;101:41. doi:10.1136 /archdischild-2015-309633

7. Morgado-Carasco D, Feola H, Vargas-Mora P. Pool palms. Dermatol Pract Concept. 2020;10:e2020009. doi:10.5826/dpc.1001a09

8. Cutrone M, Valerio E, Grimalt R. Pool palms: a case report. Dermatol Case Rep. 2019;4:1000154

9. Martína JM, Ricart JM. Erythematous-violaceous lesions on the palms. Actas Dermosifiliogr. 2009;100:507-508. 